\title{
Self-Sterilizing Polymeric Membrane Sensors Based on 6-Chloroindole Release for Prevention of Marine Biofouling
}

\author{
Tianjia Jiang, ${ }^{\S}$ Longbin Qi ${ }^{\S}$ Chao Hou, Shengtao Fang, and Wei Qin*
}

Cite This: Anal. Chem. 2020, 92, 12132-12136

Read Online

ABSTRACT: A self-sterilizing strategy based on antimicrobial organic agent release is proposed for polymeric membrane sensors to prevent marine biofouling. A solid-contact polymeric membrane calcium ion-selective electrode $\left(\mathrm{Ca}^{2+}\right.$-ISE) is selected as a model sensor. 6-Cholorindole (6-Cl indole) is utilized as the biocidal agent due to its potential antimicrobial activity and environmental friendliness. The plasticized polymeric membrane doped with 6-Cl indole shows a markedly improved antimicrobial activity against the bacterial cells collected from seawater and effectively prevents the formation of a biofilm on the sensor surface, while displaying response properties (i.e., linear range, selectivity, and response time) similar to those of the undoped membrane. Importantly, the

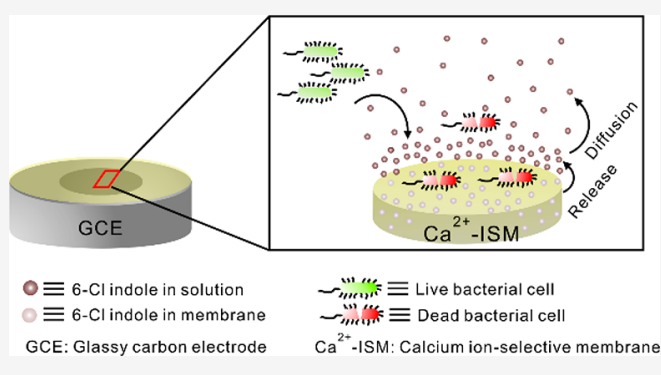
present sensor can preserve an improved antimicrobial activity when kept in the artificial seawater for 45 days, indicating highly stable antibacterial properties of the membrane electrode. Additionally, the 6-Cl indole-doped $\mathrm{Ca}^{2+}$-ISE exhibits no significant loss of analytical performance after exposure to a rather concentrated bacterial suspension $\left(\sim 10^{9}\right.$ colony-forming units per mL (CFU $\left.\mathrm{mL}^{-1}\right)$ ) for 7 days. The proposed antimicrobial agent release methodology can be extended to develop polymeric membrane-based marine sensors with stable biofouling resistances against bacterial colonization.

$\mathrm{P}$ olymeric membrane sensors have become an efficient analytical tool for assessing marine environment changes with the advantages of rapidity and simplicity as well as high accuracy. ${ }^{1-3}$ However, for long-term marine sensing, biofouling could be a serious issue. The development of marine biofouling on a surface is generally considered to follow a linear successional model, ${ }^{4-6}$ in which two crucial stages are involved, i.e., bacterial adsorption within minutes or up to hours and biofilm formation within several days. Microbial adsorption and biofilm formation usually occur on the sensor surfaces when these sensors are continuously in contact with biological foulants in seawater, ${ }^{6,7}$ thus leading to sensor failures such as a shortened lifetime and measurement errors. ${ }^{8}$ Although many approaches have been developed to improve the biocompatibilities of the polymeric membrane-based sensors for the prevention of the adsorption of proteins, lipids, and platelets in clinical samples (e.g., blood and serum), ${ }^{9-17}$ the strategies for improving their biofouling resistances in the marine environment are still rare.

Cleaning the biofouled sensors mechanically by a highpressure water jet or a brush is commonly used to remove the attached biofoulants. ${ }^{18,19}$ Despite the high removal efficiency of this simple strategy, it may suffer from problems of damaging the sensing films of the sensors, thus, changing their analysis performances and shortening their lifetimes. Another way to improve biofouling resistances is postmodification of sensor surfaces with antifouling materials for antiadhesion and bacterial inactivation, which include micro/nanostructures, ${ }^{18}$ polyethylene glycol (PEG)-based materials, ${ }^{20}$ conducting polymers, $^{21}$ and surfactants. ${ }^{22}$ Recently, we have extended this strategy to improve the environmental compatibility of a polymeric membrane-based potentiometric sensor via the surface modification with graphene oxide (GO). ${ }^{8}$ Indeed, a remarkable decrease in bacterial adsorption and an improved antimicrobial activity can be obtained with the GO-coated sensor. Although such a postmodification strategy has been successful in biofouling prevention, it is usually involved in complicated modification procedures. ${ }^{23,24}$ In addition, these modified surfaces may suffer from problems of poor adhesion between the antifouling materials and the sensor surfaces and of susceptibility of the surface modifiers (e.g., PEG) to oxidation damage, ${ }^{25,26}$ thus leading to the passivation of their antifouling functionalities.

It has been reported that antimicrobial organic agents could be incorporated into the polymeric matrixes to generate stable antimicrobial properties. ${ }^{25,27}$ Such an antimicrobial layer can be named as a self-sterilizing layer, as it could kill the microbes adjacent to the surface by slowly releasing organic biocidal agents, therefore preventing the formation of biofilms. ${ }^{28}$ Compared to other antibacterial layers based on the release

Received: July 21, 2020

Accepted: August 14, 2020

Published: August 14, 2020 
of inorganic biocides (e.g., halogens and nitric oxide), ${ }^{29,30}$ such layers based on the release of organic biocides could provide antibacterial properties over longer periods due to the hydrophobic interactions between the organic biocides and the polymeric membrane matrixes. However, the strong hydrophobic interaction may prevent the release of the antimicrobial agent from the membrane; ${ }^{25,31,32}$ therefore, biocidal agents with small molecules such as antibiotics ${ }^{33,34}$ have been used for the preparation of the self-sterilizing layers, but the continuous elution of antibiotics may lead to the development of antibiotic resistance. ${ }^{35}$ The indole derivatives have been reported as promising antimicrobial compounds with outstanding antibacterial activities and low negative environmental impacts. ${ }^{36,37}$ Some of these compounds can even be extracted from marine resources. ${ }^{38}$ Among these indole derives, 6-chloroindole (6- $\mathrm{Cl}$ indole) possesses a relatively simple molecular structure with a potential biocidal activity. ${ }^{39}$ Therefore, using $6-\mathrm{Cl}$ indole as the antimicrobial organic agent released from the polymeric sensing membrane could provide an effective protection against marine biofouling.

Herein, a simple strategy based on the release of an antimicrobial organic agent is proposed to endow a polymeric membrane-based sensor with self-sterilizing capability. A solidcontact polymeric membrane calcium ion-selective electrode $\left(\mathrm{Ca}^{2+}\right.$-ISE) is used as a model sensor. Since poly(vinyl chloride) (PVC) is the most frequently used polymer for the preparation of ISE, the PVC-based $\mathrm{Ca}^{2+}$-ISE is employed for this study. $6-\mathrm{Cl}$ indole has been used as the antimicrobial agent and incorporated into the plasticized polymeric membranes. It will be shown that the proposed $6-\mathrm{Cl}$ indole-doped potentiometric sensor can display a significantly improved antimicrobial activity for 45 days and maintain a high stability of analytical performance even in the presence of concentrated biofoulants.

\section{EXPERIMENTAL SECTION}

Membranes and Electrodes. For fabrication of the antimicrobial membranes based on $6-\mathrm{Cl}$ indole release, $6-\mathrm{Cl}$ indole was incorporated into the membrane matrix at concentrations ranging from 0.5 to $2.0 \mathrm{wt} \%$ for optimization of the membrane composition. The membrane matrix contained ETH 129, sodium tetrakis[3,5-bis(trifluoromethyl)phenyl] borate (NaTFPB), PVC, and $o$-NPOE at a fixed mass ratio of $2.3: 2.2: 31.8: 63.7$. The $6-\mathrm{Cl}$ indole-doped membrane cocktails were prepared by dissolving $360 \mathrm{mg}$ of the membrane components into $3.6 \mathrm{~mL}$ of tetrahydrofuran (THF). The antimicrobial ion-selective membranes (ISMs) were prepared by pouring the $6-\mathrm{Cl}$ indole-doped membrane cocktails into a glass ring ( $3.6 \mathrm{~cm}$ in diameter) fixed onto a glass plate. After being dried for $12 \mathrm{~h}$, the transparent membranes were obtained. The control membranes were prepared with the membrane cocktail without $6-\mathrm{Cl}$ indole using the same procedure.

Prior to the preparation of potentiometric sensors, glassy carbon electrodes (GCEs; $3.0 \mathrm{~mm}$ in diameter) were polished with alumina powder $(0.05 \mu \mathrm{m})$ and ultrasonically cleaned successively in absolute ethanol and deionized water. A poly(3,4-ethylenedioxythiophene)-poly(sodium 4-styrenesulfonate) (PEDOT-PSS) film used as the ion-to-electron transducer was modified onto the surface of the cleaned GCE. The electrochemical polymerization was performed by applying a constant current of $0.014 \mathrm{~mA}$ for $714 \mathrm{~s}$ in a solution containing $10 \mathrm{mM}$ 3,4-ethylenedioxythiophene (EDOT) and
100 mM PSS. ${ }^{40}$ Then, the modified electrodes were washed with DI water and dried overnight at room temperature. Finally, $100 \mu \mathrm{L}$ of the membrane cocktail with or without $6-\mathrm{Cl}$ indole was drop-cast on the top of the pretreated GCE to prepare the antimicrobial or control $\mathrm{Ca}^{2+}$-ISE.

\section{RESULTS AND DISCUSSION}

Sensor Design. The structural representation of the selfsterilizing solid-contact PVC-based $\mathrm{Ca}^{2+}$-ISE sensor is shown in Scheme 1a. As illustrated, the doped 6-Cl indole is slowly

Scheme 1. (a) Structural Representation of the SelfSterilizing $\mathrm{Ca}^{2+}$-ISE Based on 6-Cl Indole Release; (b) Schematic Presentation of the Antimicrobial Activity of the 6-Cl Indole-Doped $\mathrm{Ca}^{2+}$-ISM against Biofoulants

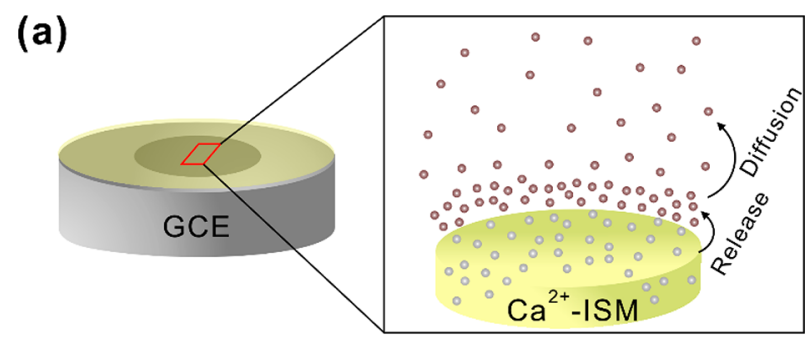

$\equiv 6-\mathrm{Cl}$ indole in solution $\quad \equiv$ $\equiv-\mathrm{Cl}$ indole in membrane

(b)

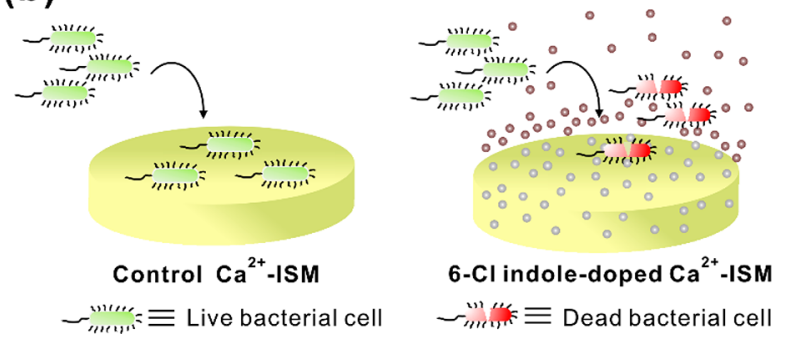

released from the membrane phase to the sensor surface and then diffused into the surrounding medium. In this case, the bacterial cells adjacent to the sensor surface can be killed by the released 6- $\mathrm{Cl}$ indole, so that the bacterial colonization on the sensor surface could be inhibited effectively (Scheme 1b). In contrast, for the case of the control $\mathrm{Ca}^{2+}$-ISE, bacterial cells could rapidly be adsorbed on the sensor surface, thus leading to sensor failures.

Influences of $6-\mathrm{Cl}$ Indole on the Sensor's Potential Response. To investigate the influence of 6- $\mathrm{Cl}$ indole on the potentiometric response, the $\mathrm{Ca}^{2+}$-ISEs with different contents of $6-\mathrm{Cl}$ indole in the ISMs were tested over the $\mathrm{Ca}^{2+}$ concentration range of $10^{-4}-10^{-1} \mathrm{M}$ in the presence of 0.5 $\mathrm{M} \mathrm{NaCl}$. As illustrated in Figure S1a, the incorporation of 6-Cl indole in the PVC-based membrane could decrease the potentiometric response to $\mathrm{Ca}^{2+}$, and such a negative effect would be more pronounced when the content of $6-\mathrm{Cl}$ indole is more than $1.0 \mathrm{wt} \%$. Indeed, the potentiometric response slope slightly decreases as the content of $6-\mathrm{Cl}$ indole in the membranes increases up to $1.0 \mathrm{wt} \%$, while further increases in the content of $6-\mathrm{Cl}$ indole lead to a remarkable decrease in the potential response, especially at high $\mathrm{Ca}^{2+}$ concentration (Figure $\mathrm{S} 1 \mathrm{~b}$ ). The $6-\mathrm{Cl}$ indole molecule has the $\mathrm{N}-\mathrm{H}$ group on the indole ring, which could work as a hydrogen bond donor for anions. ${ }^{4-43}$ In this case, the 6- $\mathrm{Cl}$ indole compound 
in the polymeric membrane could facilitate the transmembrane anion transport. With an increase in the $\mathrm{Ca}^{2+}$ concentration in aqueous solution, the counteranions (i.e., $\mathrm{Cl}^{-}$) would more easily be coextracted into the polymeric membrane along with $\mathrm{Ca}^{2+}$, thus decreasing the potential response. ${ }^{44}$ Meanwhile, the introduction of 6-Cl indole has little influence on the ion diffusion process of $\mathrm{Ca}^{2+}$ between the PVC-based membrane and the solution layer; therefore, no obvious change could be observed in the sensor's response time (Figure S2). When a long-term self-sterilizing activity for the $\mathrm{Ca}^{2+}$-ISE with less influence on the sensor's performance is considered, the weight percentage concentration of $1.0 \mathrm{wt} \%$ was selected as the optimal concentration of $6-\mathrm{Cl}$ indole in the ISMs for further experiments. Furthermore, the effect of $1.0 \mathrm{wt} \% 6-\mathrm{Cl}$ indole in the ISMs on the selectivity coefficients of the $\mathrm{Ca}^{2+}$-ISEs was evaluated; the major cations in seawater (i.e., $\mathrm{K}^{+}, \mathrm{Na}^{+}$, and $\mathrm{Mg}^{2+}$ ) were selected as the interfering ions. Indeed, the introduction of $1.0 \mathrm{wt} \% 6-\mathrm{Cl}$ indole is incapable of changing the sensor's selectivity coefficients based on the thermodynamic equilibrium response (Table S1).

Release of $6-\mathrm{CI}$ Indole from the Doped $\mathrm{Ca}^{2+}-$ ISM. The long-term 6-Cl indole release behavior was studied for 20 days, and the amounts of the released $6-\mathrm{Cl}$ indole from the proposed $\mathrm{Ca}^{2+}$-ISM were quantified by high-performance liquid chromatography. As shown in Figure S3, in the first 10 days, $6-\mathrm{Cl}$ indole is released from the doped membrane at a daily rate of about $2.0 \mathrm{wt} \%$ of the total amount of $6-\mathrm{Cl}$ indole in the membrane, and the cumulated $6-\mathrm{Cl}$ indole amount per unit surface area of the membrane increases at a rate of about 7.08 $\mu \mathrm{g} \mathrm{cm}^{-2}$ per day. Figure S3 also indicates that the daily release rate decreases slowly over the immersion time after 10 days. In addition, the cumulative amount of the released $6-\mathrm{Cl}$ indole per unit surface area is about $119.33 \mu \mathrm{g} \mathrm{cm}^{-2}$ after 20 days, which is only $33.7 \mathrm{wt} \%$ of the total amount of $6-\mathrm{Cl}$ indole in the doped membrane $\left(354 \mu \mathrm{g} \mathrm{cm}^{-2}\right)$, suggesting the feasibility of the 6-Cl indole-doped $\mathrm{Ca}^{2+}$-ISEs to provide a stable antimicrobial activity.

Antimicrobial Activities of the 6-Cl Indole-Doped $\mathrm{Ca}^{2+}$-ISM. The spatial distribution and status of the adsorbed bacterial cells on the surface of the 6-Cl indole-doped $\mathrm{Ca}^{2+}$ ISMs were observed by a confocal laser scanning microscope (CLSM) after direct contact with a bacterial suspension. As shown in Figures 1 and S4, both the live and dead bacterial cells can be observed on the control $\mathrm{Ca}^{2+}$-ISM with similar numbers, while the number of the dead bacterial cells $(\sim 1.66$ $\times 10^{5}$ cells per $\left.\mathrm{cm}^{2}\right)$ is much larger than that of the live bacterial cells $\left(\sim 0.36 \times 10^{5}\right.$ cells per $\left.\mathrm{cm}^{2}\right)$ on the $6-\mathrm{Cl}$ indoledoped $\mathrm{Ca}^{2+}$-ISM. These results show the good antimicrobial properties of the proposed sensor with $1 \mathrm{wt} \% 6-\mathrm{Cl}$ indole in the polymeric membrane. Although the bactericidal properties of 6-Cl indole have not been studied previously, it could be estimated that this compound would have an antimicrobial activity similar to that of indole based on Mitchell's chemiosmotic hypothesis. ${ }^{45,46}$ Such antimicrobial activities may be ascribed to the proton transport properties of the indole ring in the bacterial lipid membranes, which could dissipate the bacterial membrane potential, thus inhibiting bacterial growth and cell division. ${ }^{47,48}$ The antimicrobial activity of 6-Cl indole was also confirmed by the $\mathrm{CFU}$ counting method. As illustrated in Figure S5, the amount of the survival colonies for the bacterial suspension decreases by about $95 \%$ in the presence of $10 \mathrm{mg} \mathrm{mL}^{-1} 6-\mathrm{Cl}$ indole, indicating the excellent bactericidal activity of this compound.
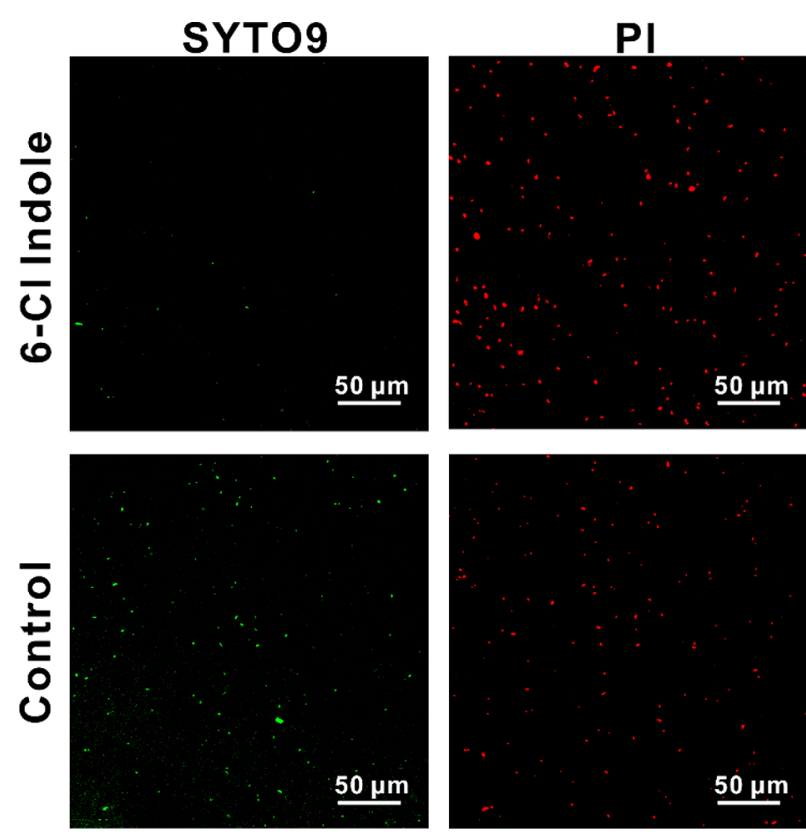

Figure 1. Representative confocal laser scanning microscope (CLSM) images of the attached marine bacterial cells on the ISMs with and without (control) 1 wt \% 6-Cl indole. The live and dead bacterial cells were stained with SYTO 9 (green) and PI (red), respectively.

Moreover, the stability of the antimicrobial properties of the proposed $\mathrm{Ca}^{2+}$-ISM was evaluated by the CFU counting method. It has been found that the proposed ISM could provide a relatively fast release of 6- $\mathrm{Cl}$ indole in the early stage of the soaking time, which may lead to a higher antimicrobial activity (Figure S3). Indeed, the survival rate of the attached bacterial cells on the 6-Cl indole-doped $\mathrm{Ca}^{2+}$-ISMs ranges from $37.4 \%$ to $50.0 \%$ in the first 13 days and thereafter increases gradually (Figure 2), which could be attributed to the slower

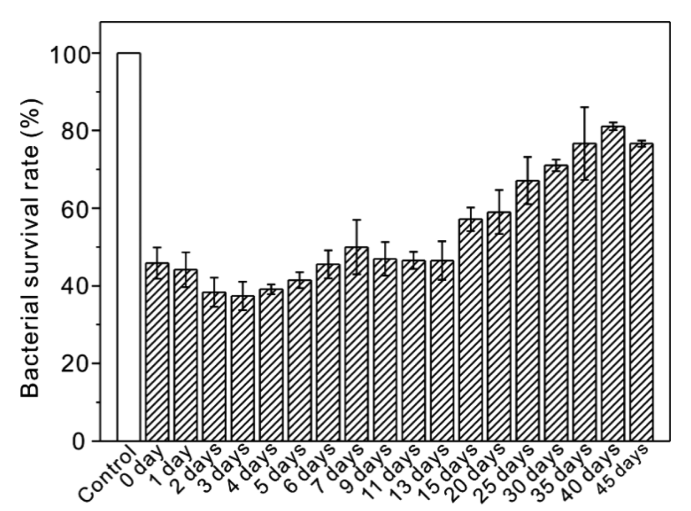

Figure 2. Stability evaluation of antimicrobial properties of the 6-Cl indole-doped $\mathrm{Ca}^{2+}$-ISM by the CFU counting method. Error bars represent one standard deviation of three measurements.

release rate because of the decreased amount of 6- $\mathrm{Cl}$ indole in the polymeric membranes. Importantly, the proposed sensor could still preserve $43.0 \%$ of the original antibacterial activity even when kept in artificial seawater for 45 days. The favorable stability of the antimicrobial activity is an important feature of a marine sensor that allows the retention of its bactericidal function for a long period of time.

Stability of the $6-\mathrm{Cl}$ Indole-Doped $\mathrm{Ca}^{2+}-$ ISEs in the Presence of Biofoulants. To illustrate the potentiometric 
response stability of the $6-\mathrm{Cl}$ indole-doped $\mathrm{Ca}^{2+}$-ISE, both the control and proposed $\mathrm{Ca}^{2+}$-ISEs were evaluated by potentiometric measurements after contact with a large amount of biofoulants. Since bacterial cells have a much higher abundance in seawater than other primary colonizers, ${ }^{49,50}$ the bacterial cells collected from seawater were selected as biofoulants for this study. All electrodes were kept in a bacterial suspension $\left(\sim 10^{9}\right.$ colony-forming units per $\mathrm{mL}$ (CFU $\left.\mathrm{mL}^{-1}\right)$ ) at $37{ }^{\circ} \mathrm{C}$ over several days before potentiometric measurements. The changes in the response slopes are shown in Figure 3, and the corresponding calibration curves of the

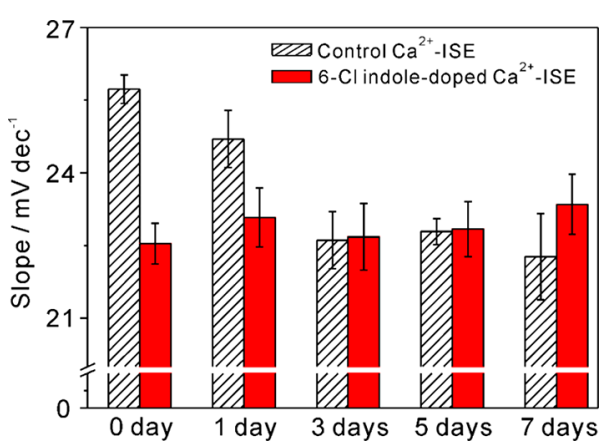

Figure 3. Potential response slopes of the control and $6-\mathrm{Cl}$ indoledoped $\mathrm{Ca}^{2+}$-ISEs after exposure to a bacterial suspension $\left(\sim 10^{9} \mathrm{CFU}\right.$ $\left.\mathrm{mL}^{-1}\right)$ at $37^{\circ} \mathrm{C}$ over several days. Error bars represent one standard deviation of three measurements.

control and proposed $\mathrm{Ca}^{2+}$-ISEs are shown in Figures $\mathrm{S} 6$ and S7, respectively. Clearly, the control $\mathrm{Ca}^{2+}$-ISE differs significantly from the 6-Cl indole-doped sensor in terms of the response slope after exposure to the biofoulants. In contrast, the response slope of the 6-Cl indole-doped sensor is almost unchanged. Such a remarkable difference is probably ascribed to the formation of a thick biofilm on the surface of the control $\mathrm{Ca}^{2+}$-ISE. In this case, the obtained potentiometric response is related to the concentration of $\mathrm{Ca}^{2+}$ in the biofouling layer instead of in the analyzed solution. ${ }^{51}$ In contrast, the antimicrobial surface of the 6-Cl indole-doped electrode can prevent the colonization and growth of the attached bacterial cells effectively; thus, the sensor still responds well to the concentration of $\mathrm{Ca}^{2+}$ in the sample.

Furthermore, such a thick biofilm formed on the surface of the control $\mathrm{Ca}^{2+}$-ISE could delay the sensor equilibration by kinetically reducing the $\mathrm{Ca}^{2+}$ ion diffusion between the ISM and the aqueous layer, ${ }^{52-54}$ leading to a remarkable increase in the sensor's response time. Indeed, the response time of the control $\mathrm{Ca}^{2+}$-ISEs appears to be significantly longer after the exposure to the biofoulants, while no obvious change is observed in the response time of the 6- $\mathrm{Cl}$ indole-doped sensor under the same conditions (Figure S8). These above results demonstrate that the $6-\mathrm{Cl}$ indole-doped $\mathrm{Ca}^{2+}$-ISE can preserve a good potentiometric response stability during the test period, even in the presence of a large amount of biofoulants.

\section{CONCLUSIONS}

Biofouling is of great concern to sensors for marine monitoring since it can impair the functions of the sensors by colonization of the bacterial cells existing in seawater, resulting in shortened sensors' usage lifetimes and a degree of errors in the collected data. In this work, a simple and robust antifouling method based on the release of an antimicrobial organic molecule (6-
$\mathrm{Cl}$ indole) has been developed to improve the environmental compatibility of a polymeric membrane calcium ion-selective electrode with no significant influences on the sensor's performance in terms of linear range, selectivity, and response time. Compared to the control electrode membrane, the proposed $6-\mathrm{Cl}$ indole-doped membrane shows remarkably improved antimicrobial properties and reliable sensing abilities after contact with a rather concentrated bacterial suspension $\left(10^{9} \mathrm{CFU} \mathrm{mL}^{-1}\right)$ for 7 days. Such antimicrobial properties could remain when the sensor is kept in artificial seawater even for 45 days. It is believed that the bactericidal organic agentreleasing strategy can provide an effective way for the design of polymeric membrane-based marine sensors with stable antimicrobial capabilities.

\section{ASSOCIATED CONTENT}

\section{Supporting Information}

The Supporting Information is available free of charge at https://pubs.acs.org/doi/10.1021/acs.analchem.0c03099.

Experimental details including materials, electrochemical measurements, antimicrobial activity evaluation, and 6$\mathrm{Cl}$ indole release measurements; potential responses of the $\mathrm{Ca}^{2+}$-ISMs with different contents of $6-\mathrm{Cl}$ indole (Figures S1 and S2); long-term release profile of 6-Cl indole (Figure S3); numbers of the live and dead bacterial cells on the ISMs as shown in Figure 1 (Figure S4); antimicrobial activity evaluation of $6-\mathrm{Cl}$ indole (Figure S5); typical calibration curves and response times of different $\mathrm{Ca}^{2+}$-ISEs after exposure to a bacterial suspension (Figures S6-S8); potentiometric selectivity coefficients of $\mathrm{Ca}^{2+}$-ISEs (Table S1) (PDF)

\section{AUTHOR INFORMATION}

\section{Corresponding Author}

Wei Qin - CAS Key Laboratory of Coastal Environmental Processes and Ecological Remediation, Yantai Institute of Coastal Zone Research (YIC), Chinese Academy of Sciences (CAS), Shandong Key Laboratory of Coastal Environmental Processes, YICCAS, Yantai, Shandong 264003, P. R. China; Laboratory for Marine Biology and Biotechnology, Pilot National Laboratory for Marine Science and Technology, Qingdao, Shandong 266237, P. R. China; Center for Ocean Mega-Science, Chinese Academy of Sciences, Qingdao, Shandong 266071, P.R. China; 이이이.org/0000-0002-9606-7730; Phone: +86-535-2109156; Email: wqin@yic.ac.cn; Fax: $+86-535-2109000$

\section{Authors}

Tianjia Jiang - CAS Key Laboratory of Coastal Environmental Processes and Ecological Remediation, Yantai Institute of Coastal Zone Research (YIC), Chinese Academy of Sciences (CAS), Shandong Key Laboratory of Coastal Environmental Processes, YICCAS, Yantai, Shandong 264003, P. R. China

Longbin Qi - CAS Key Laboratory of Coastal Environmental Processes and Ecological Remediation, Yantai Institute of Coastal Zone Research (YIC), Chinese Academy of Sciences (CAS), Shandong Key Laboratory of Coastal Environmental Processes, YICCAS, Yantai, Shandong 264003, P. R. China; University of the Chinese Academy of Sciences, Beijing 100049, P. R. China

Chao Hou - Key Laboratory of Western China's Environmental Systems (Ministry of Education), College of Earth and 
Environmental Sciences, Lanzhou University, Lanzhou, Gansu 730000, P. R. China

Shengtao Fang - CAS Key Laboratory of Coastal Environmental Processes and Ecological Remediation, Yantai Institute of Coastal Zone Research (YIC), Chinese Academy of Sciences (CAS), Shandong Key Laboratory of Coastal Environmental Processes, YICCAS, Yantai, Shandong 264003, P. R. China

Complete contact information is available at: https://pubs.acs.org/10.1021/acs.analchem.0c03099

\section{Author Contributions}

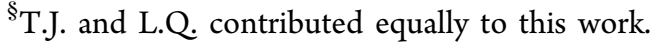

\section{Notes}

The authors declare no competing financial interest.

\section{ACKNOWLEDGMENTS}

This research was financially supported by the National Natural Science Foundation of China (41806119, 21677172), the National Key Research and Development Program of China (2016YFC1400700), the Science and Technology Project of Yantai City (2020MSGY051), the Natural Science Foundation of Shandong Province (ZR2018BB053), and the Taishan Scholar Program of Shandong Province (TSPD20181215).

\section{REFERENCES}

(1) Cuartero, M.; Pankratova, N.; Cherubini, T.; Crespo, G. A.; Massa, F.; Confalonieri, F.; Bakker, E. Environ. Sci. Technol. Lett. 2017, 4, 410-415.

(2) Zhao, G. T.; Liang, R. N.; Wang, F. F.; Ding, J. W.; Qin, W. Sens. Actuators, B 2019, 279, 369-373.

(3) Kraikaew, P.; Jeanneret, S.; Soda, Y.; Cherubini, T.; Bakker, E. ACS Sensors 2020, 5, 650-654.

(4) Chambers, L. D.; Stokes, K. R.; Walsh, F. C.; Wood, R. J. K. Surf. Coat. Technol. 2006, 201, 3642-3652.

(5) Yebra, D. M.; Kiil, S.; Dam-Johansen, K. Prog. Org. Coat. 2004, 50, $75-104$.

(6) Delauney, L.; Compere, C.; Lehaitre, M. Ocean Sci. 2010, 6, 503-511.

(7) Kroger, S.; Law, R. J. Trends Biotechnol. 2005, 23, 250-256.

(8) Jiang, T. J.; Qi, L. B.; Qin, W. Anal. Chem. 2019, 91, 1326813274 .

(9) Frost, M. C.; Rudich, S. M.; Zhang, H. P.; Maraschio, M. A.; Meyerhoff, M. E. Anal. Chem. 2002, 74, 5942-5947.

(10) Schoenfisch, M. H.; Mowery, K. A.; Rader, M. V.; Baliga, N.; Wahr, J. A.; Meyerhoff, M. E. Anal. Chem. 2000, 72, 1119-1126.

(11) Wu, Y. D.; Rojas, A. P.; Griffith, G. W.; Skrzypchak, A. M.; Lafayette, N.; Bartlett, R. H.; Meyerhoff, M. E. Sens. Actuators, B 2007, 121, 36-46.

(12) Schoenfisch, M. H.; Zhang, H. P.; Frost, M. C.; Meyerhoff, M. E. Anal. Chem. 2002, 74, 5937-5941.

(13) Wu, Y. D.; Meyerhoff, M. E. Talanta 2008, 75, 642-650.

(14) Mowery, K. A.; Schoenfisch, M. H.; Saavedra, J. E.; Keefer, L. K.; Meyerhoff, M. E. Biomaterials 2000, 21, 9-21.

(15) Jiang, X. J.; Wang, P.; Liang, R. N.; Qin, W. Anal. Chem. 2019, 91, 6424-6429.

(16) Soto, R. J.; Hall, J. R.; Brown, M. D.; Taylor, J. B.; Schoenfisch, M. H. Anal. Chem. 2017, 89, 276-299.

(17) Ghorbanizamani, F.; Timur, S. Anal. Chem. 2018, 90, 640-648.

(18) Zhang, Y. L.; Chen, L.; Lin, Z. Z.; Ding, L. J.; Zhang, X. F.; Dai,

R. H.; Yan, Q.; Wang, X. D. ACS Omega 2019, 4, 1715-1721.

(19) Whelan, A.; Regan, F. J. Environ. Monit. 2006, 8, 880-886.

(20) Hsu, L.; Selvaganapathy, P. R.; Brash, J.; Fang, Q. Y.; Xu, C. Q.; Deen, M. J.; Chen, H. IEEE Sens. J. 2014, 14, 3400-3407.
(21) Brisset, H.; Briand, J. F.; Barry-Martinet, R.; Duong, T. H.; Frere, P.; Gohier, F.; Leriche, P.; Bressy, C. Anal. Chem. 2018, 90, 4978-4981.

(22) Hu, C. G.; Yang, C. H.; Hu, S. S. Electrochem. Commun. 2007, $9,128-134$.

(23) Fan, L.; Zhang, Q.; Yang, Z.; Zhang, R.; Liu, Y. N.; He, M.; Jiang, Z.; Su, Y. ACS Appl. Mater. Interfaces 2017, 9, 13577-13586.

(24) Kang, G. D.; Cao, Y. M. Water Res. 2012, 46, 584-600.

(25) Wang, R.; Chua, K. L.; Neoh, K. G. ACS Biomater. Sci. Eng. 2015, 1, 405-415.

(26) Zhi, Z.; Su, Y.; Xi, Y.; Tian, L.; Xu, M.; Wang, Q.; Padidan, S.; Li, P.; Huang, W. ACS Appl. Mater. Interfaces 2017, 9, 10383-10397.

(27) Zelikin, A. N. ACS Nano 2010, 4, 2494-2509.

(28) Kochkodan, V.; Hilal, N. Desalination 2015, 356, 187-207.

(29) Wang, L. S.; Gupta, A.; Duncan, B.; Ramanathan, R.; Yazdani, M.; Rotello, V. M. ACS Biomater. Sci. Eng. 2016, 2, 1862-1866.

(30) Cai, W. Y.; Wu, J. F.; Xi, C. W.; Meyerhoff, M. E. Biomaterials 2012, 33, 7933-7944.

(31) Broderick, A. H.; Breitbach, A. S.; Frei, R.; Blackwell, H. E.; Lynn, D. M. Adv. Healthcare Mater. 2013, 2, 993-1000.

(32) Dave, R. N.; Joshi, H. M.; Venugopalan, V. P. Antimicrob. Agents Chemother. 2011, 55, 845-853.

(33) Wang, B. L.; Jin, T. W.; Xu, Q. W.; Liu, H. H.; Ye, Z.; Chen, H. Bioconjugate Chem. 2016, 27, 1305-1313.

(34) Hetrick, E. M.; Schoenfisch, M. H. Chem. Soc. Rev. 2006, 35, $780-789$.

(35) Zhuk, I.; Jariwala, F.; Attygalle, A. B.; Wu, Y.; Libera, M. R.; Sukhishvili, S. A. ACS Nano 2014, 8, 7733-7745.

(36) Penez, N.; Culioli, G.; Perez, T.; Briand, J.-F.; Thomas, O. P.; Blache, Y. J. Nat. Prod. 2011, 74, 2304-2308.

(37) Konya, K.; Shimidzu, N.; Miki, W.; Endo, M. Biosci., Biotechnol., Biochem. 1994, 58, 2178-2181.

(38) Omae, I. In The Handbook of environmental chemistry: Antifouling paint biocides; Springer: 2006; Vol. 5, pp 227-262.

(39) Yang, C. Y.; Yu, Y. A.; Sun, W. J.; Xia, C. H. Mar. Pollut. Bull. 2014, $88,62-69$.

(40) Bobacka, J. Anal. Chem. 1999, 71, 4932-4937.

(41) Busschaert, N.; Gale, P. A. Angew. Chem., Int. Ed. 2013, 52, $1374-1382$.

(42) Chang, K. J.; Moon, D.; Lah, M. S.; Jeong, K. S. Angew. Chem., Int. Ed. 2005, 44, 7926-7929.

(43) Pfeffer, F. M.; Lim, K. F.; Sedgwick, K. J. Org. Biomol. Chem. 2007, 5, 1795-1799.

(44) Bakker, E.; Buhlmann, P.; Pretsch, E. Chem. Rev. 1997, 97, 3083-3132.

(45) Mitchell, P. Nature 1961, 191, 144-148.

(46) Mclaughlin, S. G. A.; Dilger, J. P. Physiol. Rev. 1980, 60, 825863.

(47) Chimerel, C.; Murray, A. J.; Oldewurtel, E. R.; Summers, D. K.; Keyser, U. F. ChemPhysChem 2013, 14, 417-423.

(48) Chimerel, C.; Field, C. M.; Pinero-Fernandez, S.; Keyser, U. F.; Summers, D. K. Biochim. Biophys. Acta, Biomembr. 2012, 1818, 15901594.

(49) Qian, P. Y.; Lau, S. C. K.; Dahms, H. U.; Dobretsov, S.; Harder, T. Mar. Biotechnol. 2007, 9, 399-410.

(50) Dang, H. Y.; Lovell, C. R. Appl. Environ. Microbiol. 2000, 66, 467-475.

(51) Boswell, P. G.; Buhlmann, P. J. Am. Chem. Soc. 2005, 127, $8958-8959$.

(52) Radomska, A.; Singhal, S.; Ye, H.; Lim, M.; Mantalaris, A.; Yue, X. C.; Drakakis, E. M.; Toumazou, C.; Cass, A. E. G. Biosens. Bioelectron. 2008, 24, 435-441.

(53) Lisak, G.; Arnebrant, T.; Lewenstam, A.; Bobacka, J.; Ruzgas, T. Anal. Chem. 2016, 88, 3009-3014.

(54) Smith, M. J.; Kerr, A.; Cowling, M. J. J. Environ. Monit. 2007, 9, $1378-1386$. 